\title{
Influence of Water and Air Flow on the Performance of Cellulose Evaporative Cooling Pads USED IN MEDiterRaneAN GreENHOUSES
}

\author{
A. Franco, D. L. Valera, A. Madueño, A. Peña
}

\begin{abstract}
Evaporative cooling systems are a widely used technique in Mediterranean greenhouses. In this study, the cellulose evaporative cooling pads most commonly used in this region were tested in the laboratory using a new methodology in a wind tunnel to determine the water flow on the pad and air flow through it, as well as the water consumption and pressure drop caused by each pad as a function of air speed. Greater water flow increased the pressure drop, but the main effect on performance was caused by modifying the air flow through the pad. We recommend a range of air speeds through the pad of 1 to $1.5 \mathrm{~m} \mathrm{~s}^{-1}$, at which the pressure drop was between 3.9 and $11.25 \mathrm{~Pa}$, depending on the type of pad and the water flow applied. On the other hand, saturation efficiency ranged between $64 \%$ and $70 \%$, while the amount of evaporated water varied between 1.8 and $2.62 \mathrm{~kg} \mathrm{~h}^{-1} \mathrm{~K}^{-1}$ per square meter of pad area.
\end{abstract}

Keywords. Evaporated water, Evaporative cooling, Fan and pad, Greenhouse, Heat and mass transfer, Pressure drop, Saturation efficiency.

$\mathrm{E}$ vaporative cooling is a simple and economic cooling technique that has been used for centuries to reduce ambient temperatures to comfortable levels (Watt and Brown, 1997). Willits (2003), Lertsatitthanakorn et al. (2006), Sethi and Sharma (2007a), and Haeussermann et al. (2007), among others, have shown that these systems substantially improve climate control in greenhouses and intensive livestock installations.

The operation of evaporative cooling systems starts during the spring and summer in regions like southeast Spain, which has a high concentration of greenhouses and high temperatures during this period. Furthermore, these systems are not used solely to reduce temperature, but rather to maintain suitable humidity conditions. This is of particular interest for crops during early developmental stages when they have little foliage and are transplanted in regions where the outside temperature is high and relative humidity low at this time of year. Using this system in Almería (Spain), for example, the transplant date of some autumn-winter crops can be brought forward to the month of August, when temperatures are extremely high (Valera et al., 2008). In the province of Almería, there are more than 27,000 ha of greenhouses, and in the last few years manufacturers from Almería have been exporting their greenhouse techniques to other countries and climatic

Submitted for review in May 2009 as manuscript number SE 8041; approved for publication by the Structures \& Environment Division of ASABE in March 2010.

The authors are Antonio Franco, Lecturer, EUITA, University of Sevilla, Spain; Diego L. Valera, ASABE Member Engineer, Professor, Department of Rural Engineering, University of Almería, Spain; Antonio Madueño, Associate Professor, EUITA, University of Sevilla, Spain; and Araceli Peña, Professor, Department of Rural Engineering. University of Almería, Spain. Corresponding author: Diego L. Valera, Department of Rural Engineering, University of Almería, Carretera de Sacramento, s/n. 04120 Almería, Spain; phone: +34-950015546; fax: +34-950015491; e-mail:dvalera@ual.es. regions, such as Mexico, Colombia, Morocco, and China (Molina et al., 2004).

Although many cooling or humidification systems use evaporative techniques, the most popular techniques in greenhouses are fog systems combined with natural ventilation, and cooling pads combined with forced ventilation (Arbel et al., 2003). Cooling and humidification are two of the major applications in protected horticulture (Li and Willits, 2008).

Evaporative cooling systems are based on the evaporation of water inside the greenhouse, producing lower temperature and higher humidity. The change from liquid to vapor requires energy, which is extracted from the greenhouse air, cooling it and increasing its humidity. This brings about a change from sensitive heat (drop in temperature) to latent heat (increase in water content in the mix of humid air). In thermodynamics, this is known as the adiabatic process, and the enthalpy remains practically constant (ASHRAE, 2005).

The efficiency of these systems is affected under conditions of high ambient humidity, such as in coastal regions. However, as the humidity in the greenhouse varies considerably throughout the day, evaporative cooling systems are more effective and more necessary during the middle of the day, when the ambient temperature is high and relative humidity is lower. A recent study by Dagtekin et al. (2009) of evaporative cooling systems in the Mediterranean region found that these systems are effective when the relative humidity drops below $50 \%$. They are of particular interest in hot regions with strong winds (e.g., Almería, Spain), since a fog system requires the windows to be open. If the wind speed is high, the windows must be closed to safeguard the greenhouse structure; this causes rapid saturation of the air in the greenhouse, and the fog system is no longer effective. However, an evaporative cooling system functions correctly almost irrespective of the outside air speed.

An evaporative pad is a permeable screen of porous material that is saturated with water by an irrigation system 
installed at the top. As ventilation air passes through the pad, the water evaporates, initially producing a drop in the temperature of the air entering the greenhouse. As the incoming air mixes with the warm inside air, the greenhouse environment is cooled.

The pads are located along all or part of the side of the greenhouse, usually on the northern side to avoid shade in the northern hemisphere. It is also recommended to place them opposite the prevailing wind direction during the summer. On the opposite side of the greenhouse, powerful ventilation fans are installed to generate the suction necessary for the outside air to enter the greenhouse, after passing through the pads. This air must pass through the pads and exit through the fans. Consequently, this system requires tight structures to prevent any non-humidified air from entering. This limitation has meant that in structures that are not very tight, as is the case of the Almería greenhouse, another system that is not so demanding in this respect is recommended, i.e., a fog system. The evaporative cooling system is completed with a device for recirculating water. This device consists of a hydraulic pump, distribution pipes directing the water to the top of the pads, a gutter to collect and recycle excess drainage water, and a water storage reservoir.

The pad-and-fan system has the advantage of functional simplicity, and it involves no risk of wetting the leaves of the crop, thus reducing the incidence of fungal diseases. Its main drawbacks are the temperature and humidity gradients that are produced inside the greenhouse (Kittas et al., 2001). To reduce these, it is recommended to use the pad-and-fan system in combination with shade screens (Kittas et al., 2003). According to some authors, other challenges include the installation costs and the water and energy consumption, which are considerable, although less than for fog systems (Sethi and Sharma, 2007b). Despite these drawbacks, the use of evaporative pads is a useful alternative in greenhouse cooling.

The constantly rising energy costs and shortages of water resources in regions of intensive production in southeastern Spain force growers to use evaporative cooling systems in order to save on both water and energy. Choosing a suitable evaporative pad requires knowledge of the different working parameters. ANSI and ASABE (ANSI/ASABE Standards, 2008) recommend air speed values and minimum water flows for only four different types of pad: aspen fiber pads of 50 and $100 \mathrm{~mm}$ thickness mounted vertically $\left(0.76 \mathrm{~m} \mathrm{~s}^{-1}\right.$ air speed and $5 \mathrm{~L} \mathrm{~min}^{-1} \mathrm{~m}^{-1}$ minimum water flow rate per unit length of pad in desert conditions) and corrugated cellulose pads of 100 and $150 \mathrm{~mm}$ thickness $\left(1.27 \mathrm{~m} \mathrm{~s}^{-1}\right.$ and $1.78 \mathrm{~m} \mathrm{~s}^{-1}$ air speed, respectively, and 6.2 and $9.9 \mathrm{~L} \mathrm{~min}^{-1} \mathrm{~m}^{-1}$ minimum water flow rate per unit length of pad, respectively). For proper designs, the ASABE guidelines (ASABE Standards, 2008) for selection of energy-efficient agricultural ventilation fans should also be taken into consideration.

Al-Sulaiman (2002) evaluated the cooling efficiency of evaporative pads consisting of local fibers such as jute fibers, palm fibers, and luffa gourd fibers, recording values of $62.1 \%, 38.9 \%$, and $49.9 \%$, respectively. Gunhan et al. (2007) analyzed the efficiency and pressure drop in pads of three thicknesses $(50,100$, and $150 \mathrm{~mm})$ made from volcanic rocks such as volcanic tuff, and compared the results with commercial pads made of corrugated cellulose. They found that volcanic tuff is a good alternative to CELdek corrugated cellulose for air speeds up to $0.6 \mathrm{~m} \mathrm{~s}^{-1}$. Dowdy et al. (1986) obtained non-dimensional correlations of the coefficients of heat and mass transfer in evaporative pads made of aspen fiber. The correlations can be used to size evaporative cooling equipment based on a given air velocity and pad efficiency. Liao and Chiu (2002) carried out the same analysis for fine and coarse fabric PVC sponge pads, obtaining saturation efficiency values between $76.68 \%$ and $91.64 \%$ and pressure drops between 10 and $110 \mathrm{~Pa}$ for the three thicknesses (50, 100 , and $150 \mathrm{~mm}$ ) and air speeds between 0.75 and $1.5 \mathrm{~m} \mathrm{~s}^{-1}$.

The vast majority of new greenhouses constructed in the Mediterranean region incorporate evaporative cooling systems with pads made of corrugated cellulose. The present study therefore focuses on the performance of this type of pad, analyzing the different commercial models available in the market.

Studies of the performance of corrugated cellulose pads have been carried out previously, showing the influence of face air velocity and the angle and the thickness of the pad on the saturation efficiency and pressure drop (Koca et al., 1991). The pads consist of layers of corrugated cellulose, with alternating angles of incidence above and below the horizontal. The saturation efficiency is the ratio between the drop in air temperature after passing through the pad and the maximum possible drop under conditions of air saturation. Dowdy and Karabash (1987) determined experimentally the coefficients of heat and mass transfer and obtained nondimensional correlations for the design of industrial evaporative cooling systems.

The pad's water consumption is another important parameter, due to the shortage of this resource and because it determines the dimensions of both the pump system and the tank for water recirculation. The amount of water evaporated by the pad is related to the outside air temperature and relative humidity, as well as to the geometric characteristics of the pad and the air speed through it. Sabeh et al. (2007) proved that total daily water use increases linearly with ventilation rates, finding values between 3.2 and $10.3 \mathrm{~L} \mathrm{per}^{2}$ of greenhouse area for $150 \mathrm{~mm}$ cellulose pads in semi-arid conditions. Values between 7.9 and $16.3 \mathrm{~L} \mathrm{~m}^{-2}$ were obtained by Al-Helal (2007) in extremely arid conditions with a $100 \mathrm{~mm}$ thick pad of corrugated cellulose.

Therefore, the present work has two main objectives. The first objective is to obtain, under laboratory conditions, the basic design equations that relate the geometry of the pads with the water and air flow through them, as well as with the pressure drop and coefficients of heat and mass transfer, using four different commercial pads of corrugated cellulose. The second objective is to quantify the effect of each type of pad and of air speed on the saturation efficiency and water consumption.

\section{Materials ANd Methods}

\section{TEST EQUIPMENT}

To determine the influence of air and water flow on the performance of cellulose evaporative pads, a low-speed open-circuit wind tunnel was used with a circular crosssection of $38.8 \mathrm{~cm}$ diameter (fig. 1). The wind tunnel was designed and constructed in the Department of Rural Engineering of the University of Almería (Valera et al., 2006). A uniform and stable air flow was achieved (as reported by Fang et al., 2001) under controlled conditions of temperature and humidity. 


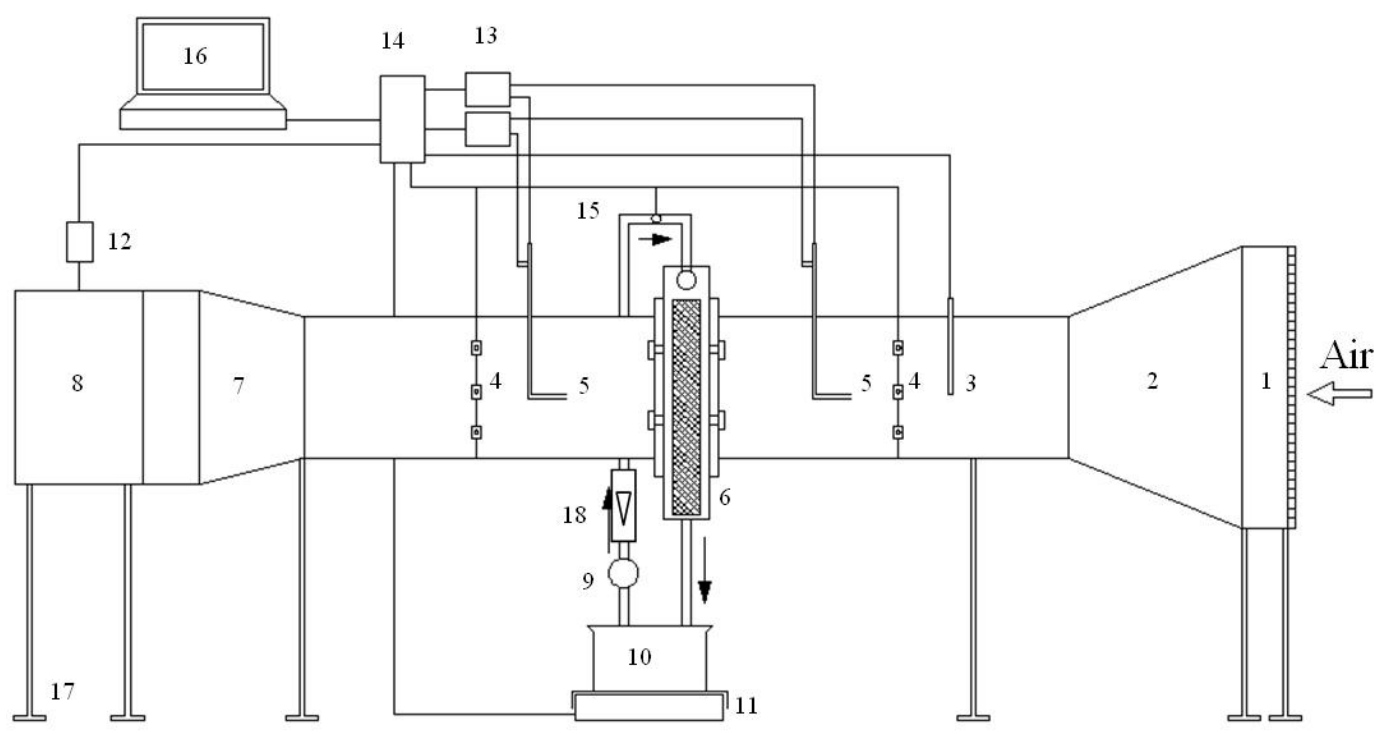

Figure 1. Schematic of the wind tunnel with controlled water and air flow rate (not to scale): $1=$ air flow stabilizer, $2=$ contraction section, $3=$ hot-wire anemometer, $4=$ temperature and humidity sensors, $5=$ Pitot-Prandtl tube, $6=$ frame with cellulose pad, $7=$ diffuser, $8=$ fan, $9=$ pump, $10=$ tank, $11=$ scale, 12 = inverter, 13 = differential pressure transducer, $14=$ micrologger, $15=$ water temperature sensor, $16=$ computer, $17=$ support legs, and $18=$ rotameter (flowmeter).

Air flow was supplied by a centrifugal fan (HCT-45-2T-3/AL, Sodeca S.A., Sant Quirze de Besora, Spain) with a capacity of $12,800 \mathrm{~m}^{3} \mathrm{~h}^{-1}$ and a diameter of $460 \mathrm{~mm}$, driven by a $2.2 \mathrm{~kW}$ variable-speed three-phase electric motor $(230 \mathrm{~V}$ and $50 \mathrm{~Hz})$. An AC inverter (Micromaster 420, Siemens España S.A., Madrid, Spain) was used for speed control, with an output frequency of 0 to $50 \mathrm{~Hz}$ and a setpoint resolution of 0 to $1 \mathrm{~Hz}$. This allowed the fan speed to be decreased from 2,865 to $0 \mathrm{rpm}$ by means of a digital microprocessor. The inverter was connected to the computer through a micrologger and digital/analog (D/A) converter that received digital control signals from the personal computer (PC) and sent analog signals to the frequency inverter. The static pressure drop through the test section was measured by a differential pressure transducer (SI 727, SI-Special Instruments, Nörlingen, Germany) connected to two Pitot tubes (Airflow Developments, Ltd., Buckinghamshire, U.K.) of $4 \mathrm{~mm}$ diameter, one $450 \mathrm{~mm}$ upstream and one $450 \mathrm{~mm}$ downstream from the middle of the test section. The transducer measurement range was 0 to $200 \mathrm{~Pa}$ with an accuracy of $\pm 0.25 \%$ full scale (f.s.), hysteresis and reproducibility of $\pm 0.1 \%$ f.s., and temperature error of $\pm 0.025 \%$ per ${ }^{\circ} \mathrm{C}$, and a 0 to $10 \mathrm{~V}$ signal output. The real-time readings were stored on the hard disk of a personal computer via the data acquisition unit. Air velocity and temperature transmitters (EE70-VT32C5, Elektronik, Engerwitzdort, Austria) were placed $950 \mathrm{~mm}$ upstream from the measurement section and were equipped with a directional hot-film anemometer with a working range of 0 to $10 \mathrm{~m} \mathrm{~s}^{-1}$ and accuracy of $\pm 0.1 \mathrm{~m} \mathrm{~s}^{-1}$ for air velocity measurements. Although the air velocity may be calculated from the pressure differential between the two orifices of a Pitot-static tube connected across a pressure transducer, hot-film anemometers supply fast-response velocity measurements in turbulent flows. Moreover, although the Pitot tube connected to the differential pressure transducer provides a very accurate indirect measurement of air velocity for high values, for air velocity below $8 \mathrm{~m} \mathrm{~s}^{-1}$ the pressure system is less accurate than the anemometer (Valera et al., 2006; Molina et al., 2006).

In order to carry out tests with evaporative pads in the wind tunnel, a specific test frame was designed to incorporate the pads (fig. 2). This frame consisted of a galvanized metal

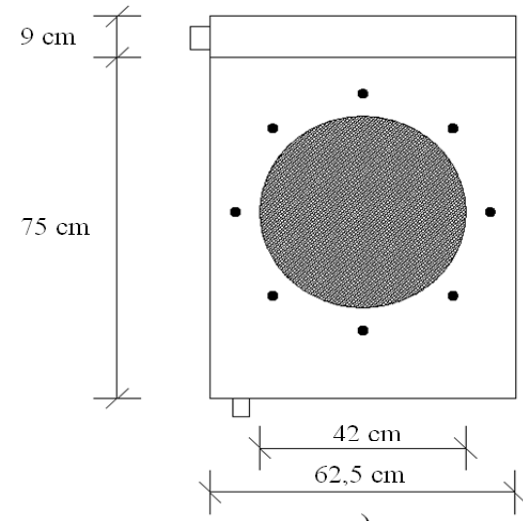

a)

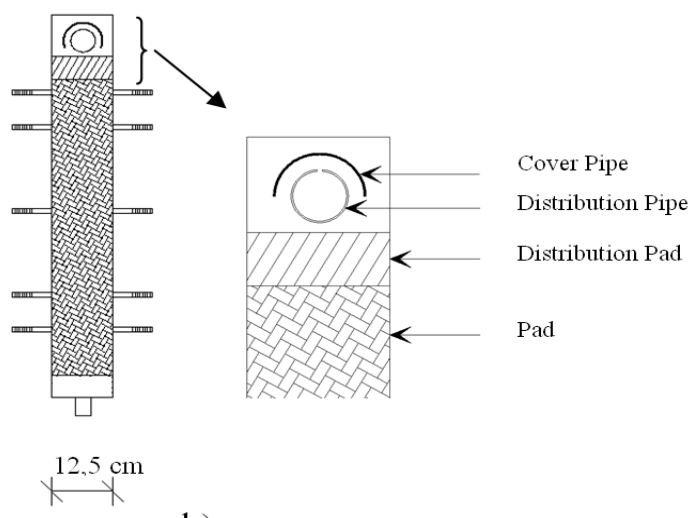

b)

Figure 2. Evaporative pad tests: (a) frame dimensions, (b) water distribution. 
structure with a water distribution system incorporated into the top part. The water distribution system was constructed of a $20 \mathrm{~mm}$ diameter PVC pipe with $2 \mathrm{~mm}$ holes $65 \mathrm{~mm}$ apart. In the lower part of the frame, a water collection system allowed water to drain by gravity into a tank, before being recycled by a $12 \mathrm{~V}$ axial pump. Water flow at the entrance was controlled by varying the voltage of the continuous-current hydraulic pump and readings from the rotameter (flowmeter) with an average range of 3 to $22 \mathrm{~L} \mathrm{~m}^{-1}$ per minute and an error of $\pm 4 \%$.

As well as measuring air speed and pressure drop, the tests also reported data on the temperature and humidity of the air flow before and after passing through the pad material, as well as of the temperature of the recirculated water and the mass flow of evaporated water.

The temperature and humidity of the air current were measured using six digital relative humidity/temperature sensors (SHT75 series, Sensirion, Zurich, Switzerland) with 9-bit digital output and an accuracy of $\pm 1.8 \%$ for relative humidity and $\pm 0.3^{\circ} \mathrm{C}$ for temperature. These sensors do not require calibration. The sensors were located in groups of three, $700 \mathrm{~mm}$ upstream and downstream from the sample to be tested. They were mounted on two rods placed across the width of the test section (fig. 1). Data were obtained on the humidity and temperature of the air flow both before and after it passed through the evaporative pad (Hu and Huang, 2005).

The temperature of the water in the recirculation circuit was measured at three different points: at the entrance to and exit from the pad, and in the recirculation tank. For this purpose, we used digital thermometers (DS18S20, Maxim Integrated Products, Sunnyvale, Cal.) that provided 9-bit temperature measurements. These sensors communicated over a bus that required only one data line (and ground) for communication with a central microprocessor. Their operational temperature range was $-55^{\circ} \mathrm{C}$ to $+125^{\circ} \mathrm{C}$, with an accuracy of $\pm 0.5^{\circ} \mathrm{C}$ over the range of $-10^{\circ} \mathrm{C}$ to $+85^{\circ} \mathrm{C}$. To calculate the mass flow of evaporated water $\left(\mathrm{kg} \mathrm{h}^{-1}\right.$ per $\mathrm{m}^{2}$ of pad area), we used a scale that measured the weight of the water in the recirculation tank. For this purpose we used a CTC load cell of $50 \mathrm{~N}$ capacity, specially designed to work in traction and compression, with gauges to measure shear strain, and a VMA-10 signal conditioner (both from Dinacell Electrónica, Madrid, Spain).

The signals that the sensors emitted were recorded by means of an electric circuit designed ad hoc with eight analog inputs with a resolution of 10 bits, six digital inputs for the humidity/temperature sensors, and an input for the three temperature probes controlled by a bus. The flow of control and data was managed by an RS-232C connection to a PC.

\section{Pad Types and Test Procedure}

The pads are the most important element in the exchange of heat and mass, fulfilling two main functions. First, they provide the largest possible surface for the exchange of crossflows of water and air. Second, they delay the fall of water, ensuring that the exchange process lasts longer. This leads to an increase in the heat given off by the water to the nonsaturated air. The cooling capacity of an evaporative pad depends on its shape and the material it is made of (cellulose, plastic, glass fiber, etc.) and on the air and water flow through it.

More and more high-technology greenhouses are being installed in the Mediterranean region and are incorporating

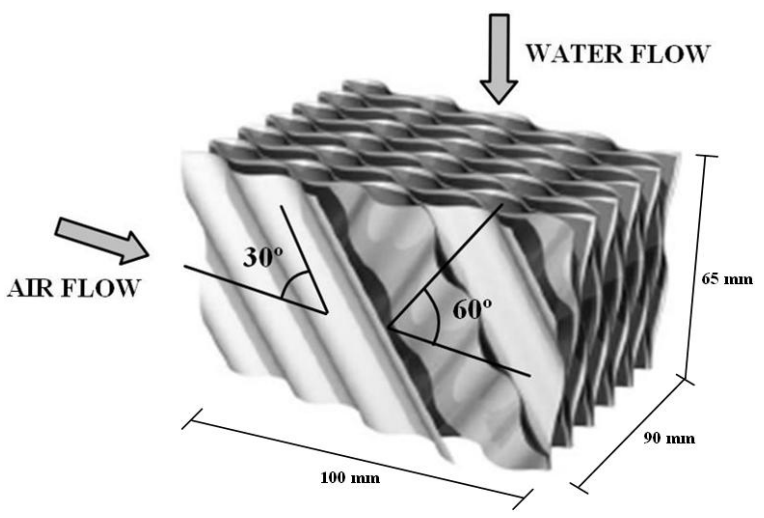

Figure 3. Example of a $60^{\circ}-30^{\circ} 100 \mathrm{~mm}$ thick cellulose panel.

evaporative cooling systems, such as evaporative pads with forced ventilation (Kittas et al, 2005). The type of pad most commonly used is made of corrugated cellulose sheets, and so these pads have been chosen for the present study. They consist of layers of corrugated cellulose, with alternating angles of incidence above and below the horizontal (fig. 3). The aim of this design is to provide a greater transfer surface $\left(\mathrm{m}^{2} \mathrm{~m}^{-3}\right)$, greater mechanical resistance, and low resistance to the passage of air and water. The length and width of the undulation of the sheets, together with the angles of incidence and the thickness of the pad, are the characteristic geometric parameters. These parameters define the form and shape of the undulation in the cellulose sheet. In a cross-section of a sheet perpendicular to the direction of the undulation, the length of the undulation is the distance between two consecutive crests, and the width of the undulation is the vertical distance between the upper crest and the next lower trough.

Four commercial models of evaporative pads made by two different manufacturers were tested. These are the most commonly used models in the Mediterranean region. The manufacturer G\&R (Gigola and Riccardi, Italy) commercializes a $100 \mathrm{~mm}$ thick model with angles of $45^{\circ}-45^{\circ}$, while Munters (Kista, Sweden) markets three models, two with angles of $60^{\circ}-30^{\circ}$ that are 50 and $100 \mathrm{~mm}$ thick, and one with angles of $45^{\circ}-45^{\circ}$ that is $100 \mathrm{~mm}$ thick, but with length and width of undulations different from the G\&R model. Three different samples of each type were tested in the wind tunnel. These samples were $0.60 \mathrm{~m}$ wide by $0.65 \mathrm{~m}$ high, i.e., more than the minimum height of $0.60 \mathrm{~m}$ as recommended by ANSI and ASABE (ANSI/ASABE Standards, 2008).

A detailed study was made of the geometric characteristics of the cellulose pads tested. The geometric parameters are as follows: angles of incidence of the sheets that make up the pads $\left({ }^{\circ}\right)$, thickness of the pad $(\mathrm{mm})$, number of sheets per meter of pad width $\left(u d, \mathrm{~m}^{-1}\right)$, thickness of the sheets $(\mathrm{mm})$, undulation length $(\mathrm{mm})$, undulation width $(\mathrm{mm})$, specific area of the pad $\left(\mathrm{m}^{2} \mathrm{~m}^{-3}\right)$, porosity $\left(\mathrm{m}^{3} \mathrm{~m}^{-3}\right)$, and a nondimensional geometric parameter $\left(l_{e} / l\right)$, where $l_{e}$ is the characteristic length $(\mathrm{m})$ and $l$ is the thickness of the panel $(\mathrm{m})$. The characteristic length $(\mathrm{m})$ is defined as $l_{e}=V / A_{s}=A-1$, where $V$ is the volume occupied by the porous medium $\left(\mathrm{m}^{3}\right)$, $A_{S}$ is the area of transfer of the pad $\left(\mathrm{m}^{2}\right)$, and $A$ is the specific area of the pad or the area per unit of pad volume $\left(\mathrm{m}^{2} \mathrm{~m}^{-3}\right)$. For the length and width of the undulation of the sheets, the caliper and thickness were measured with a micrometer. To calculate the specific area, we used image software. Finally, the dry porosity was calculated as one minus the ratio be- 
Table 1. Characteristics of the cellulose pads tested.

\begin{tabular}{|c|c|c|c|c|c|c|c|c|c|}
\hline Manufacturer & $\begin{array}{c}\text { Pad } \\
\text { Thickness } \\
(\mathrm{mm})\end{array}$ & $\begin{array}{c}\text { Angles } \\
\left({ }^{\circ}\right)\end{array}$ & $\begin{array}{l}\text { No. of } \\
\text { Sheets } \\
\left(\mathrm{m}^{-1}\right)\end{array}$ & $\begin{array}{l}\text { Thickness } \\
\text { of Sheets } \\
(\mathrm{mm})\end{array}$ & $\begin{array}{l}\text { Length of } \\
\text { Undulation } \\
(\mathrm{mm})\end{array}$ & $\begin{array}{l}\text { Width of } \\
\text { Undulation } \\
(\mathrm{mm})\end{array}$ & $\begin{array}{c}\text { Specific } \\
\text { Area } \\
\left(\mathrm{m}^{2} \mathrm{~m}^{-3}\right)\end{array}$ & $\begin{array}{c}l_{e} / l \\
\left(\times 10^{-2}\right)\end{array}$ & $\begin{array}{c}\text { Dry } \\
\text { Porosity } \\
\left(\mathrm{m}^{3} \mathrm{~m}^{-3}\right)\end{array}$ \\
\hline G\&R & 100 & $45^{\circ}-45^{\circ}$ & 157 & 0.213 & 19.5 to 19.5 & 6.37 to 6.37 & 391.114 & 2.557 & 0.957 \\
\hline Munters & 100 & $45^{\circ}-45^{\circ}$ & 142 & 0.228 & 20.5 to 20.5 & 7.00 to 7.00 & 347.114 & 2.888 & 0.959 \\
\hline Munters & 100 & $60^{\circ}-30^{\circ}$ & 132 & 0.192 to 0.191 & 18.5 to 17 & 7.50 to 7.50 & 361.516 & 2.766 & 0.965 \\
\hline Munters & 50 & $60^{\circ}-30^{\circ}$ & 208 & 0.222 to 0.219 & 12 to 11 & 4.80 to 4.80 & 556.752 & 3.592 & 0.937 \\
\hline
\end{tabular}

tween the solid volume and the total volume of the pad. Table 1 shows the geometric characteristics obtained in our study.

The pads were immersed in water for $24 \mathrm{~h}$ before each test in order for them to be totally saturated. Four different water flow rates were tested, both above and below the $6.2 \mathrm{~L} \mathrm{~min}^{-1}$ $\mathrm{m}^{-1}$ minimum recommended by ANSI and ASABE (ANSI/ ASABE Standards, 2008) for $100 \mathrm{~mm}$ thick corrugated vertical cellulose pads. These flow rates were 5, 6.6, 8.3, and $10 \mathrm{~L}$ $\mathrm{min}^{-1}$ per linear meter of pad mounted vertically. Expressed in terms of flow rate per exposed surface area of pad $\left(\mathrm{m}^{2}\right)$ in the test, these numbers were $0.128,0.171,0.214$, and $0.256 \mathrm{l} \mathrm{s}^{-1} \mathrm{~m}^{-2}$, respectively.

These flow rates were kept constant by varying the pressure of the hydraulic pump using a power source and adjusting the flow rate based on readings from the rotameter. The experiment was also repeated with a dry pad solely to test the pressure drop of the air passing through it.

The air flow through the pad was regulated by controlling the fan speed, taking continuous measurements with a hotwire anemometer. The range of air speed for the test was set between 0.3 and $4 \mathrm{~m} \mathrm{~s}^{-1}$.

At the start of the test, the water flow was fixed. After $10 \mathrm{~min}$, the fan was started at an initial velocity of approximately $0.3 \mathrm{~m} \mathrm{~s}^{-1}$, increasing by $0.6 \mathrm{~m} \mathrm{~s}^{-1}$ up to $4 \mathrm{~m} \mathrm{~s}^{-1}$. Increments in speed were separated by 5 min intervals so that equilibrium could be achieved between the pad and the new air and water conditions. At each air speed, 100 data were recorded by all the sensors at $3 \mathrm{~s}$ intervals.

\section{Mathematical Model}

In order to determine experimentally the heat and mass transfer coefficients in the evaporative pads, we used a semi-empirical expression derived from the design of evaporative cooling systems, based on the water and energy balances between the wet surface of the pad and the air flow (Dowdy and Karabash, 1987; Liao and Chiu, 2002).

We first consider the energy balance for the mixture of dry air and water vapor as:

$$
q=m_{a} h_{a 1}+m_{v 1} h_{v 1}+m_{e} h_{w b}-m_{a} h_{a 2}-m_{v 2} h_{v 2}
$$

where $m_{e}$ is the flow of evaporated water $\left(\mathrm{kg} \mathrm{h}^{-1}\right) ; m_{a}$ is the mass flow of incoming air $\left(\mathrm{kg} \mathrm{h}^{-1}\right): m_{a}=\rho_{a} \cdot Q_{a}$, in which $\rho_{a}$ is the air density $\left(\mathrm{kg} \mathrm{m}^{-3}\right)$ and $Q_{a}$ is the air flow through the pad $\left(\mathrm{m}^{3} \mathrm{~h}^{-1}\right) ; m_{v 1}$ and $m_{v 2}$ are the flows of vapor at the entrance and exit of the pad, respectively $\left(\mathrm{kg} \mathrm{h}^{-1}\right) ; q$ is the flow of transferred heat (W); $h_{a 1}$ and $h_{a 2}$ are the specific enthalpy of dry air at the entrance and exit of the pad, respectively $\left(\mathrm{kJ} \mathrm{kg}^{-1}\right)$; $h_{v 1}$ and $h_{v 2}$ are the enthalpy of saturated water vapor at the entrance and exit of the pad, respectively $\left(\mathrm{kJ} \mathrm{kg}^{-1}\right)$; and $h_{w b}$ is the enthalpy of saturated water vapor at the wet bulb temperature of the incoming air $\left(T_{w b}\right)\left(\mathrm{kJ} \mathrm{kg}^{-1}\right)$.

We then apply the water vapor balance:

$$
m_{e}=m_{v 2}-m_{v 1}
$$

Dividing equation 2 by $m_{a}$ we obtain:

$$
m_{e}=m_{a}\left(W_{2}-W_{1}\right)
$$

After dividing equation 1 by $m_{a}$ and substituting it into equation 3, assuming it is an ideal gas for both dry air and water vapor, the following equation is obtained:

$$
\begin{aligned}
q & =m_{a} C_{p a}\left(T_{1}-T_{2}\right)+m_{a} \\
& \times\left[W_{1}\left(h_{v 1}-h_{w b}\right)-W_{2}\left(h_{v 2}-h_{w b}\right)\right]
\end{aligned}
$$

where $C_{p a}$ is the specific heat of dry air $\left(\mathrm{kJ} \mathrm{kg}^{-1} \mathrm{~K}^{-1}\right), T_{1}$ is the dry temperature of the incoming air $(\mathrm{K}), T_{2}$ is the dry temperature of the outgoing air $(\mathrm{K}), T_{w b}$ is the thermodynamic temperature of the wet bulb at the entrance, and $W_{1}$ and $W_{2}$ are the absolute humidity of the air at the entrance and exit of the pad, respectively $\left(\mathrm{kg}_{w} \mathrm{~kg}_{a}{ }^{-1}\right)$.

Using the product of the coefficient of heat transfer and the log mean temperature difference $\left(\Delta T_{l m}\right.$, in $\left.\mathrm{K}\right)$ and the product of the mass transfer coefficient and the average logarithmic difference in the density of water vapor $\left(\Delta \rho_{v}\right.$, in $\left.\mathrm{kg} \mathrm{m}^{-3}\right)$, we can express equations 3 and 4 as:

$$
\begin{aligned}
& q=h_{H} A_{s} \Delta T_{l m} \\
& m_{e}=h_{M} A_{s} \Delta \rho_{v}
\end{aligned}
$$

where $h_{H}$ is the coefficient of heat transfer $\left(\mathrm{W} \mathrm{m}^{-2} \mathrm{~K}^{-1}\right), h_{M}$ is the coefficient of mass transfer $\left(\mathrm{m} \mathrm{s}^{-1}\right)$, and $A_{s}$ is the pad area of transfer $\left(\mathrm{m}^{2}\right)$. By simplifying we obtain:

$$
\begin{aligned}
& h_{H}=\frac{q}{A_{s} \Delta T_{l m}} \\
& h_{M}=\frac{m_{e}}{A_{s} \Delta \rho_{v}}
\end{aligned}
$$

The log mean temperature difference and the log mean mass difference in the density of water vapor can be expressed as:

$$
\begin{gathered}
\Delta T_{l m}=\frac{\left(T_{2}-T_{1}\right)}{\ln \left(\left(T_{2}-T_{w b}\right) /\left(T_{1}-T_{w b}\right)\right)} \\
\Delta \rho_{v}=\frac{\left(\rho_{v 2}-\rho_{v 1}\right)}{\ln \left(\left(\rho_{v 1}-\rho_{w b}\right) /\left(\rho_{v 2}-\rho_{w b}\right)\right)}
\end{gathered}
$$

where $\rho_{v 1}$ and $\rho_{v 2}$ are the density of water vapor before and after the pad, respectively $\left(\mathrm{kg} \mathrm{m}^{-3}\right)$, and $\rho_{w b}$ is the density of saturated water vapor at the wet bulb temperature $\left(\mathrm{kg} \mathrm{m}^{-3}\right)$.

This experimental approach implies measuring the coefficients of heat and mass transfer under laboratory conditions and later correlating the data obtained in terms of appropriate non-dimensional parameters. This method was applied to the different pad geometries and flow conditions. 
One way of correlating heat and mass transfer by forced convection in outside cross-flows passing through a circular and irregular surface, similar to that of the pads, is to use Hilpert correlations (Incropera and DeWitt, 1999):

$$
\begin{aligned}
& \mathrm{Nu}=C_{1} \operatorname{Re}^{m_{1}} \operatorname{Pr}^{1 / 3} \\
& \mathrm{Sh}=C_{2} \operatorname{Re}^{m_{2}} \operatorname{Sc}^{1 / 3}
\end{aligned}
$$

where $\mathrm{Nu}$ is the Nusselt number, Re is the Reynolds number, $\mathrm{Pr}$ is the Prandtl number, Sh is the Sherwood number, Sc is the Schmidt number, and $C_{1}, C_{2}, m_{1}$, and $m_{2}$ are constants.

The definition of the above-mentioned non-dimensional numbers is expressed in the following equations:

$$
\begin{gathered}
\mathrm{Nu}=\frac{h_{H} \cdot l_{e}}{k} \quad \operatorname{Re}=\frac{v \cdot l_{e}}{v} \quad \operatorname{Pr}=\frac{v}{\alpha} \\
\mathrm{Sh}=\frac{h_{M} \cdot l_{e}}{D} \quad \mathrm{Sc}=\frac{v}{D}
\end{gathered}
$$

where $v$ is velocity $\left(\mathrm{m} \mathrm{s}^{-1}\right) ; l_{e}$ is the characteristic length (m) defined as $l_{e}=V / A_{s}=A-1$, where $V$ is the volume occupied by the porous medium $\left(\mathrm{m}^{3}\right), A_{S}$ is the area of transfer of the pad $\left(\mathrm{m}^{2}\right)$, and $A$ is the specific area of the pad or the area per unit of pad volume $\left(\mathrm{m}^{2} \mathrm{~m}^{-3}\right) ; v$ is the kinetic viscosity of the dry air $\left(\mathrm{m}^{2} \mathrm{~s}^{-1}\right) ; k$ is the thermal conductivity of the dry air $\left(\mathrm{W} \mathrm{m} \mathrm{m}^{-1} \mathrm{~K}^{-1}\right)$; $\alpha$ is the thermal diffusivity $\left(\mathrm{m}^{2} \mathrm{~s}^{-1}\right)$; and $D$ is the coefficient of diffusivity of the water vapor in the air $\left(\mathrm{m}^{2} \mathrm{~s}^{-1}\right)$. To calculate these parameters, we used a set of expressions that are the result of the thermophysical properties of the air and the pressure of water vapor (ASHRAE, 2005).

Using equations 11 and 12 , it is possible to obtain the values of $C_{1}$ and $m_{1}$ and the values of $C_{2}$, and $m_{2}$ as linear relationships between $\left(\mathrm{Nu} \mathrm{Pr}^{-1 / 3}\right)$ and $\mathrm{Re}$ and between $\left(\mathrm{Sh} \mathrm{Sc}^{-1 / 3}\right)$ and $\mathrm{Re}$, respectively, for each of the pads tested.

Dowdy and Karabash (1987) used corrugated cellulose pads with the same geometry but different thickness, and they were able to add a non-dimensional parameter to equations 11 and 12 that is characteristic of the geometry of the pads. This parameter is the ratio between the characteristic length $\left(l_{e}\right)$ and the thickness of the pad $(l)$ to the power of an exponent. Liao and Chui (2002) performed a similar experiment but with evaporative pads made of different materials of three thicknesses and two different geometries using the correlation of Zhukauskas (1972). In the present study, the Hilpert correlations will be obtained using a fit of least squares, introducing the non-dimensional geometric parameter $\left(l_{e} / l\right)$ but using four evaporative cellulose pads of different geometries and thicknesses.

Milosavljevic and Heikkilä (2001) proposed another way of correlating the measurements of pressure drop and the transfer coefficients with the flows involved in the evaporative process and the geometries of the pads for cooling towers. For the pressure drop, they used:

$$
\Delta P=k_{1}\left(\frac{l_{e}}{l}\right)^{a_{1}}\left(1+Q_{w}^{b_{1}}\right) v^{2}
$$

For the coefficients of heat and mass transfer, the correlations were as follows:

$$
h_{H}=k_{2}\left(\frac{l_{e}}{l}\right)^{a_{2}}\left(1+Q_{w}^{b_{2}}\right) v^{c_{2}}
$$

$$
h_{M}=k_{3}\left(\frac{l_{e}}{l}\right)^{a_{3}}\left(1+Q_{w}^{b_{3}}\right) v^{c_{3}}
$$

where $\Delta P$ is the pressure drop caused by the pads $(\mathrm{Pa}), Q_{w}$ is the mass flow of water applied per unit of exposed surface of pad $\left(\mathrm{kg} \mathrm{s}^{-1} \mathrm{~m}^{-2}\right), v$ is the air speed through the pad $\left(\mathrm{m} \mathrm{s}^{-1}\right)$, and $\left(l_{e} / l\right)$ is the non-dimensional geometric parameter of the pads. The parameters $k_{i}, a_{i}, b_{i}$, and $c_{i}$ of equations 14,15 , and 16 were obtained using a non-linear regression analysis.

On the other hand, the cooling efficiency $(\eta)$ was determined as the ratio between the drop in air temperature after passing through the pad and the maximum possible drop under conditions of air saturation:

$$
\eta=\frac{T_{1}-T_{2}}{T_{1}-T_{w b}}
$$

The value of cooling efficiency depends on the air speed through the pad, the specific surface of the pad (wet surface), and the water/air ratio $\left(m_{w} / m_{a}\right)$.

Finally, we can also define the evaporated water $\left(C_{w}\right)$ of the pads $\left(\mathrm{kg} \mathrm{h}^{-1} \mathrm{~m}^{-2} \mathrm{~K}^{-1}\right)$, expressed as the mass flow of evaporated water per unit of exposed surface $\left(A_{f}\right)$ and the maximum thermal difference possible given the air conditions of air entering the pad:

$$
C_{w}=\frac{m_{e}}{\left(T_{1}-T_{2}\right) A_{f}}
$$

Substituting equation 17 in equation 18, the pad's evaporated water depends on the air speed through it, the saturation efficiency of the pad, and the air conditions on entering the pad:

$$
C_{w}=\frac{m_{e}}{\eta\left(T_{1}-T_{w b}\right) A_{f}}
$$

\section{Results AND Discussion}

\section{Pressure Drop Caused by the Cellulose Pads}

For the four types of cellulose pads, we observed that after increasing the water flow, there was a greater pressure drop for a given air speed through the pad. This is due to the reduction in the pad's porosity $\left(\mathrm{m}^{3} \mathrm{~m}^{-3}\right)$, since the increase in water flow increases the sheet of water on the inside transfer surface and reduces the volume of air per unit of pad volume. Figure 4 shows the results obtained in the wind tunnel for the four models.

With the results obtained, the pressure drop was correlated with the pad geometry and air and water flows using equation 14, and we determined parameters $k_{1}, a_{1}$, and $b_{1}$ by means of non-linear regression analysis on the data. The following universal pressure drop expression was obtained for cellulose pads, regardless of their geometry or water and air flow:

$$
\Delta P=0.768\left(\frac{l_{e}}{l}\right)^{-0.469}\left(1+Q_{w}^{1.139}\right) v^{2}, \mathrm{R}^{2}=0.987
$$

We deduced, therefore, that the lower the value of the geometric parameter $\left(l_{e} / l\right)$, the greater the pressure drop for the air flowing through the pad. The pad's non-dimensional geometric parameter $\left(l_{e} / l\right)$ is lower when the thickness $(l)$ and 

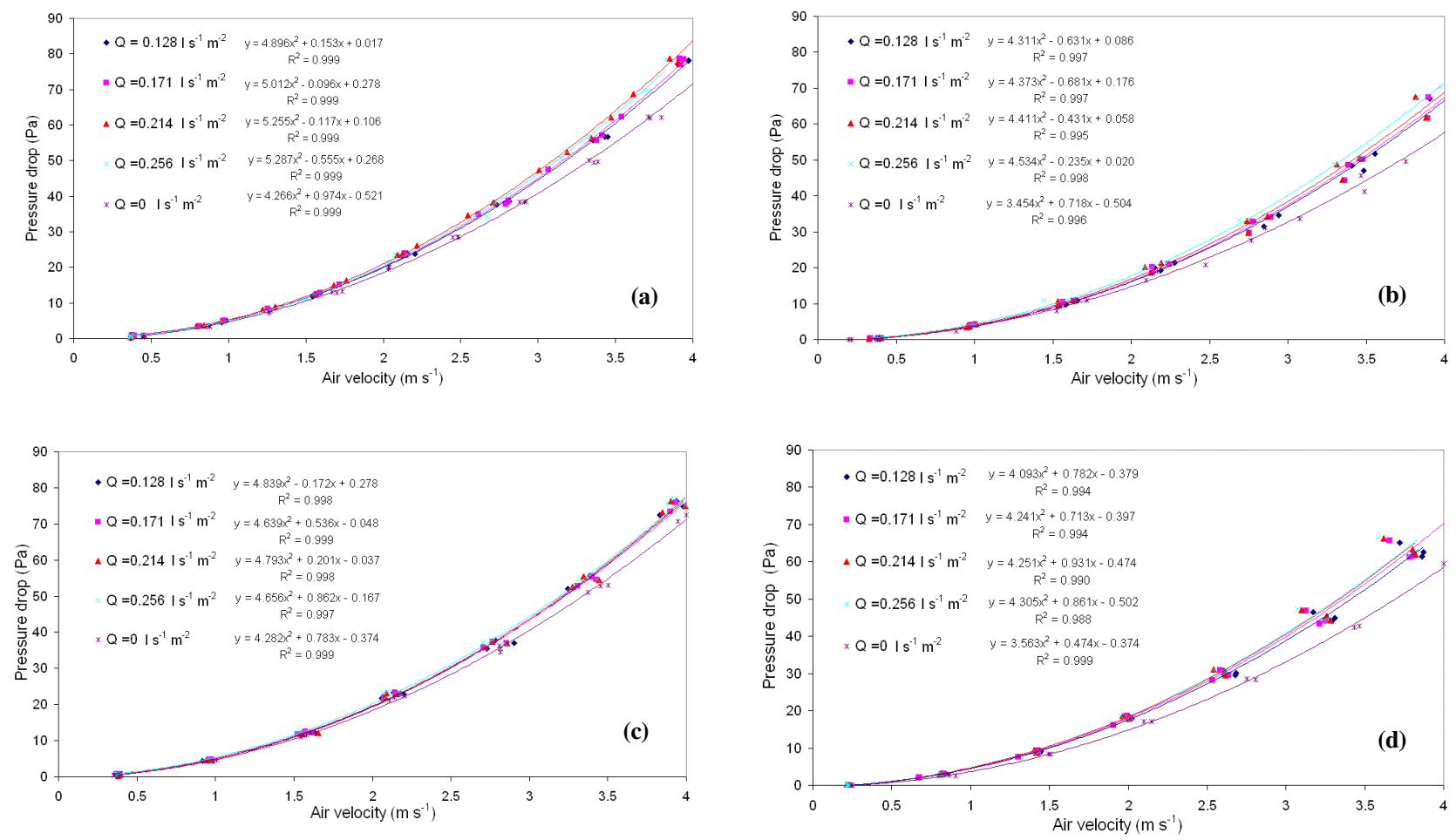

Figure 4. Effect of the air speed and volumetric flow of water through the pad on pressure drop for the (a) $45^{\circ}-45^{\circ} 100 \mathrm{~mm}$ (G\&R), (b) $45^{\circ}-45^{\circ} 100 \mathrm{~mm}$ (Munters), (c) $60^{\circ}-30^{\circ} 100 \mathrm{~mm}$ (Munters), and (d) $60^{\circ}-30^{\circ} 50 \mathrm{~mm}$ (Munters) pads.

surface area $(A)$ are greater, as the porosity $(\theta)$ is less. Similar results were obtained by Koca et al. (1991) and Beshkani and Hosseini (2006). The same occurred with the water flow. The greater the water flow, the greater the pressure drop, as the sheet of water flowing over the transfer surface increases, thereby decreasing the volume of air, and as a result the porosity of the pad. This is contrary to the results obtained by El-Dessouky et al. (1996) for structured packing.

The results show that the pressure drop increases in the four cellulose pads at greater air speed (fig. 5) and water flow (fig. 6). At air speed of $1 \mathrm{~m} \mathrm{~s}^{-1}$, the pressure drop varied between 3.9 and $5.04 \mathrm{~Pa}$, while at $1.5 \mathrm{~m} \mathrm{~s}^{-1}$ it varied between 9.07 and $11.25 \mathrm{~Pa}$, for all rates of water flow. If we compare the $100 \mathrm{~mm}$ thick pads, the $45^{\circ}-45^{\circ} \mathrm{G} \& \mathrm{R}$ pad exhibited the largest resistance: $19.54 \%$ to $45.24 \%$ larger than the $45^{\circ}-45^{\circ}$ Munters pad, because it is less porous, and $0.25 \%$ to $4.53 \%$ larger than the $60^{\circ}-30^{\circ}$ Munters pad. Comparing pads with the same angle but different thickness, the $100 \mathrm{~mm}$ pad exhibited $11.12 \%$ to $34.74 \%$ more resistance than the $50 \mathrm{~mm}$ pad.

\section{Heat and Mass Transfer Coefficients}

By calculating the heat and mass transfer coefficients for the four types of evaporative cellulose pads tested, and varying the flows of water and air passing through them, we can study the influence of these flows and of the geometry of the pads on the transfer processes. Using equations 15 and 16 and carrying out a non-linear regression analysis, we obtained the values of the parameters $k_{2}$ and $k_{3}$ and of the exponents $a_{2}, b_{2}, c_{2}$ and $a_{3}, b_{3}, c_{3}$, respectively. Tables 2 and 3 show the values and the influence of the exponents on the flows and geometry of the pads in the heat and mass transfer processes, respectively.
From the results obtained, we can deduce that the heat and mass transfer coefficients are influenced by the air speed through the pads, but not by the water flow applied to the previously saturated pads. Tables 2 and 3 show that the estimated values of the exponents $b_{2}$ and $b_{3}$, respectively, are very close to zero or they include zero in their confidence intervals. El-Dessouky et al. (1996) obtained similar results for structured porous pads. Therefore, eliminating the independent variable $Q_{w}$ (mass water flow) from equations 15 and 16, and correlating the data once again, we obtain the universal expressions for the coefficients of heat and mass transfer as a function of the geometry of the pads and the air speed through them:

$$
h_{H}=358.226\left(\frac{l_{e}}{l}\right)^{0.611} v^{0.785}, \mathrm{R}^{2}=0.988
$$

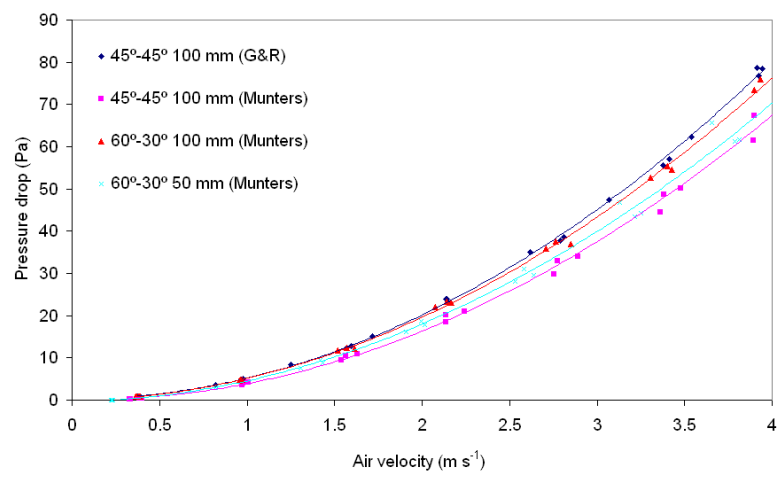

Figure 5. Effect of air speed through the pad on pressure drop produced by the four cellulose pads tested for a water mass flow rate of $0.171 \mathrm{~kg} \mathrm{~s}^{-1}$ per $\mathbf{m}^{-2}$ of pad area. 

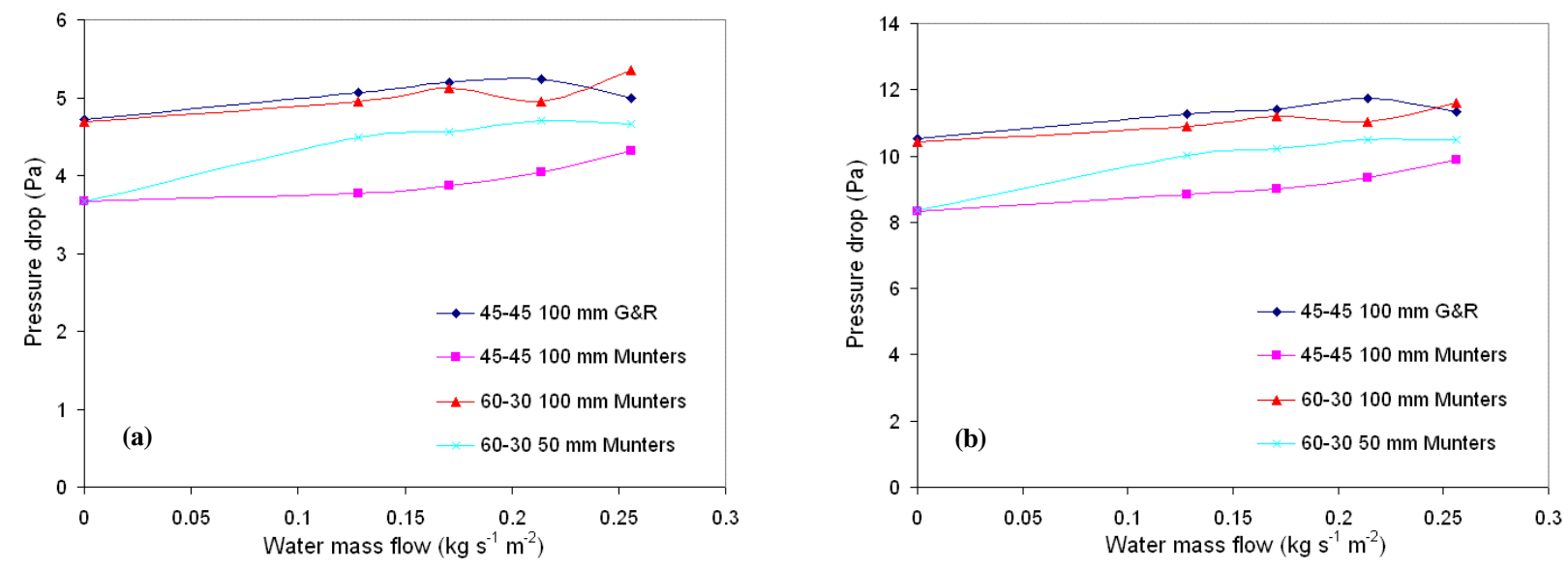

Figure 6. Effect of the flow of water on pressure drop produced by the four cellulose pads tested at air speeds of: (a) $1 \mathrm{~m} \mathrm{~s}^{-1}$, and (b) $1.5 \mathrm{~m} \mathrm{~s}$.

$$
h_{M}=0.356\left(\frac{l_{e}}{l}\right)^{0.682} v^{0.696}, \mathrm{R}^{2}=0.943
$$

This is of great importance, as we can reduce the water flow applied to the pads, providing it remains greater than the amount of evaporated water, without altering the pad's heat and mass transfer to the air. This allows us to reduce the size of the components for wetting the pads and to use less water. As an added bonus, the pressure drop of the air passing through the pad will be reduced.

Figures 7 and 8 shows the influence of air speed on the coefficients of heat and mass transfer, respectively, in the four models of evaporative cellulose pads and for all the water flows tested. Comparing the heat transfer coefficients of each pad model, we can observe, as mentioned above, that they increase, fitting an exponential expression as a function of air speed through the pad. The $60^{\circ}-30^{\circ} 50 \mathrm{~mm}$ pad exhibited the highest values for heat transfer coefficient, $20 \%$ to $40 \%$ higher than the $60^{\circ}-30^{\circ} 100 \mathrm{~mm}$ pad, and $30 \%$ to $50 \%$ higher than the two $45^{\circ}-45^{\circ}$ pads. The latter two hardly showed significant differences at air speed over $2 \mathrm{~m} \mathrm{~s}^{-1}$. The mass transfer coefficient shows a similar behavior on the heat

Table 2. Parameter values representing the influence of the pad geometry and of the air and water flows on the heat transfer coefficients.

\begin{tabular}{|c|c|c|c|c|c|}
\hline \multirow[b]{2}{*}{ Parameter } & \multirow[b]{2}{*}{ Estimate } & \multirow{2}{*}{$\begin{array}{c}\text { Asymptotic } \\
\text { Standard } \\
\text { Error }\end{array}$} & \multicolumn{2}{|c|}{$\begin{array}{c}\text { Asymptotic } 95 \% \\
\text { Confidence Interval }\end{array}$} & \multirow[b]{2}{*}{$\mathrm{R}^{2}$} \\
\hline & & & Lower & Upper & \\
\hline$k_{2}$ & 191.114 & 14.495 & 162.595 & 219.633 & \multirow{4}{*}{0.988} \\
\hline$a_{2}$ & 0.614 & 0.021 & 0.574 & 0.654 & \\
\hline$b_{2}$ & 0.069 & 0.024 & 0.022 & 0.116 & \\
\hline$c_{2}$ & 0.786 & 0.007 & 0.772 & 0.799 & \\
\hline
\end{tabular}

Table 3. Parameter values representing the influence of the pad geometry and of the air and water flows on the mass transfer coefficients.

\begin{tabular}{cccccc}
\hline & & $\begin{array}{c}\text { Asymptotic } \\
\text { Standard }\end{array}$ & \multicolumn{2}{c}{$\begin{array}{c}\text { Asymptotic 95\% } \\
\text { Confidence Interval }\end{array}$} & \\
\cline { 4 - 5 } Parameter & Estimate & Error & Lower & Upper & \multirow{2}{*}{$\mathrm{R}^{2}$} \\
\hline$k_{3}$ & 0.168 & 0.026 & 0.118 & 0.219 & \\
$a_{3}$ & 0.679 & 0.042 & 0.597 & 0.761 & \multirow{2}{*}{0.943} \\
$b_{3}$ & -0.052 & 0.039 & -0.130 & 0.026 & \\
$c_{3}$ & 0.696 & 0.013 & 0.670 & 0.722 & \\
\hline
\end{tabular}

transfer coefficient. The $60^{\circ}-30^{\circ} 50 \mathrm{~mm}$ pad exhibited the highest values for the mass transfer coefficient, $10 \%$ to $12 \%$ higher than the $60^{\circ}-30^{\circ} 100 \mathrm{~mm}$ pad, and $24 \%$ to $30 \%$ and $27 \%$ to $33 \%$ higher than the two $45^{\circ}-45^{\circ}$ pads.

If we introduce a non-dimensional geometric parameter $\left(l_{e} / l\right)$ related to the thickness and the specific area of the pad (figs. $9 \mathrm{~b}$ and $9 \mathrm{~d}$ ) into equations 11 and 12 , we obtain the following non-dimensional correlations calibrated by the heat and mass transfer coefficients, respectively.

The non-dimensional correlations that include the nondimensional geometric parameter of the pads were obtained by means of a fit of least squares (figs. 9a and 9c):

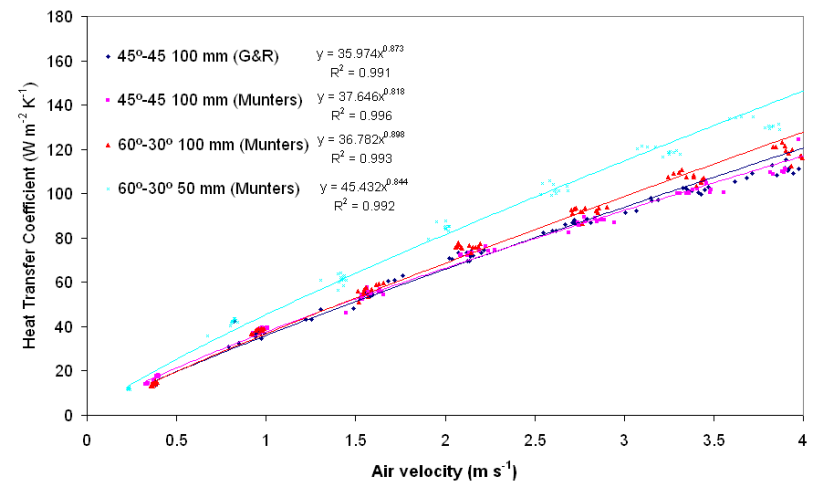

Figure 7. Relationship between the heat transfer coefficient and the air speed for the four types of evaporative cellulose pads.

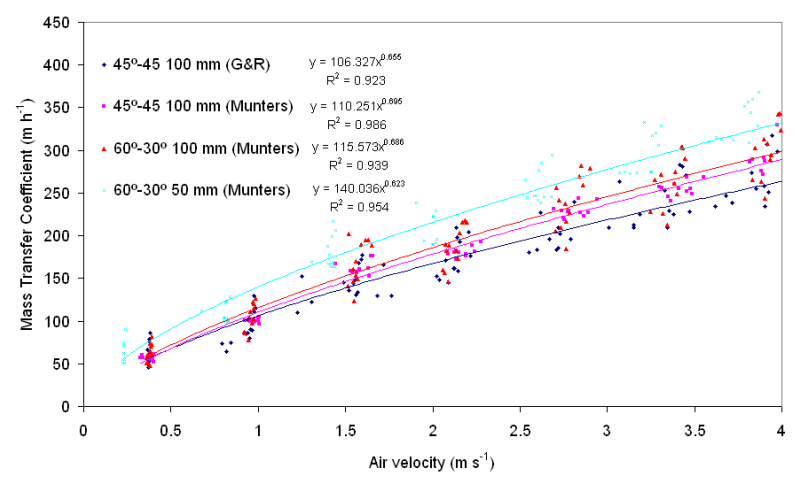

Figure 8. Relationship between the mass transfer coefficient and the air speed for the four types of evaporative cellulose pads. 


$$
\begin{aligned}
& \mathrm{Nu}=0.172\left(\frac{l_{e}}{l}\right)^{0.32} \mathrm{Re}^{0.85} \operatorname{Pr}^{1 / 3}, \mathrm{R}^{2}=0.991 \\
& \mathrm{Sh}=0.141\left(\frac{l_{e}}{l}\right)^{0.32} \mathrm{Re}^{0.85} \mathrm{Sc}^{1 / 3}, \mathrm{R}^{2}=0.923
\end{aligned}
$$

Assuming that heat and mass transfer occur in a given flow regime at similar rates, they give rise to an analogy between those processes in the following way (Holman, 2001):

$$
\frac{h_{H}}{h_{M}}=\rho_{a} C_{p a} \mathrm{Le}^{2 / 3}
$$

where Le is the Lewis number $(\mathrm{Le}=\alpha / D)$. Dividing equation 23 by equation 24 gives us a similar expression for the evaporative cellulose pads:

$$
\frac{h_{H}}{h_{M}}=1.371 \rho_{a} C_{p a} L e^{2 / 3}, \mathrm{R}^{2}=0.917
$$

Assumed for equation 25 is that the amount of turbulent momentum and the diffusivity of heat and mass are the same (Incropera and DeWitt, 1999). Therefore, it is reasonable to expect small differences between experimental and predicted values.

\section{Air SATURATion EfFiciency}

As a general characteristic, we can say that as air speed increases, the duration of contact between the air and the water decreases. As a result, there is a lower degree of air saturation, and therefore less saturation efficiency. The same occurs with the specific surface of the pad $\left(\mathrm{m}^{2} \mathrm{~m}^{-3}\right)$. The smaller the specific surface $(A)$, the less area for contact between water and air, and therefore less air saturation efficiency. Considering the water flow, and according to the
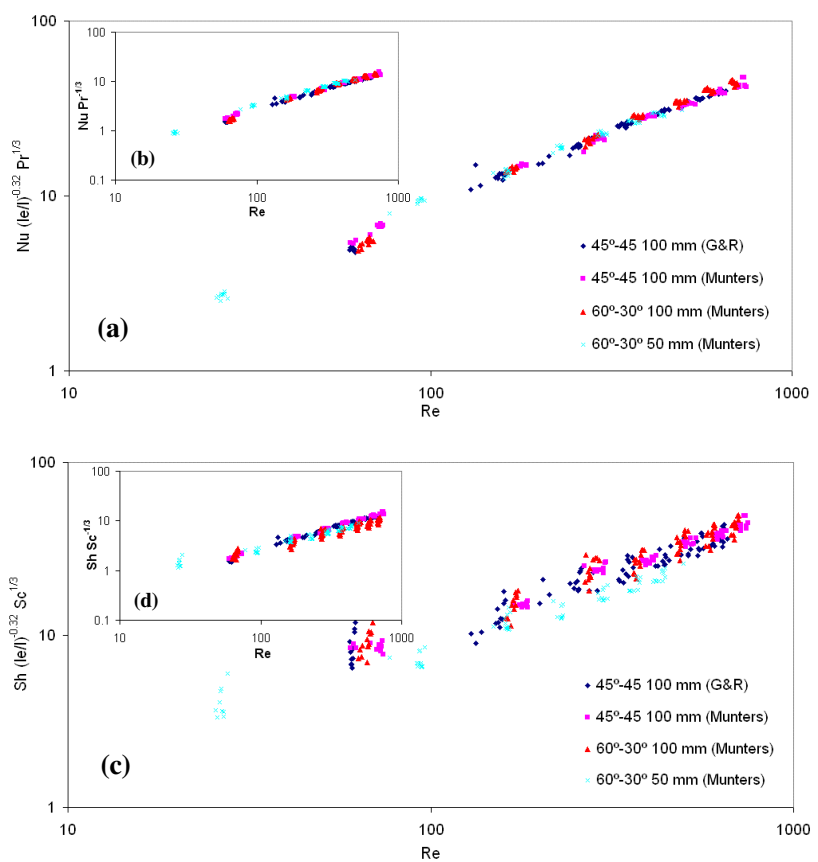

Figure 9. Non-dimensional correlations of the heat transfer coefficients: (a) calibrated, and (b) non-calibrated; and of mass transfer coefficients: (c) calibrated and (d) non-calibrated. results obtained, the saturation efficiency remains constant when the water flow applied to the pad varies. This can be seen in figure 10 for air speeds of 1 and $1.5 \mathrm{~m} \mathrm{~s}^{-1}$, respectively. Thus, the saturation efficiency is not influenced by the water flow, as was the case for the coefficients of heat and mass transfer reported above.

Figure 11 shows the saturation efficiency at different air speeds through the four pad types tested and for all the water flow rates applied. The maximum air saturation efficiency occurs at the lowest air speeds (around $0.5 \mathrm{~m} \mathrm{~s}^{-1}$ ), reaching $71 \%$ for the two $45^{\circ}-45^{\circ} 100 \mathrm{~mm}$ pads, $70 \%$ and $69 \%$ for the $60^{\circ}-30^{\circ} 50 \mathrm{~mm}$ and $100 \mathrm{~mm}$ pads, respectively. Comparing the three $100 \mathrm{~mm}$ pads, the saturation efficiency of the $45^{\circ}-45^{\circ} \mathrm{G} \& \mathrm{R}$ pad is $1.12 \%$ to $3.25 \%$ higher than the $60^{\circ}-30^{\circ}$ pad, and $0.63 \%$ to $8.58 \%$ higher than the $45^{\circ}-45^{\circ}$ Munters pad. Regarding the two pads with the same angle of incidence $\left(60^{\circ}-30^{\circ}\right)$, the $50 \mathrm{~mm}$ pad is slightly better than the $100 \mathrm{~mm}$ pad $(2 \%)$, but only at air speeds of less than $0.7 \mathrm{~m} \mathrm{~s}^{-1}$. At higher air speeds, the $100 \mathrm{~mm}$ pad is up to $10.84 \%$ more efficient.

According to the results obtained, the saturation efficiency was correlated to the geometry of the pads and the air speed through the pads by means of non-linear regression analysis of the data, obtaining the following expression:

$$
\eta=34.966\left(\frac{l_{e}}{l}\right)^{-0.183} v^{-0.076}, \mathrm{R}^{2}=0.751
$$

\section{Water Evaporated from the PAds}

The water evaporated from the pads is a very important parameter due to the shortage of this resource and also
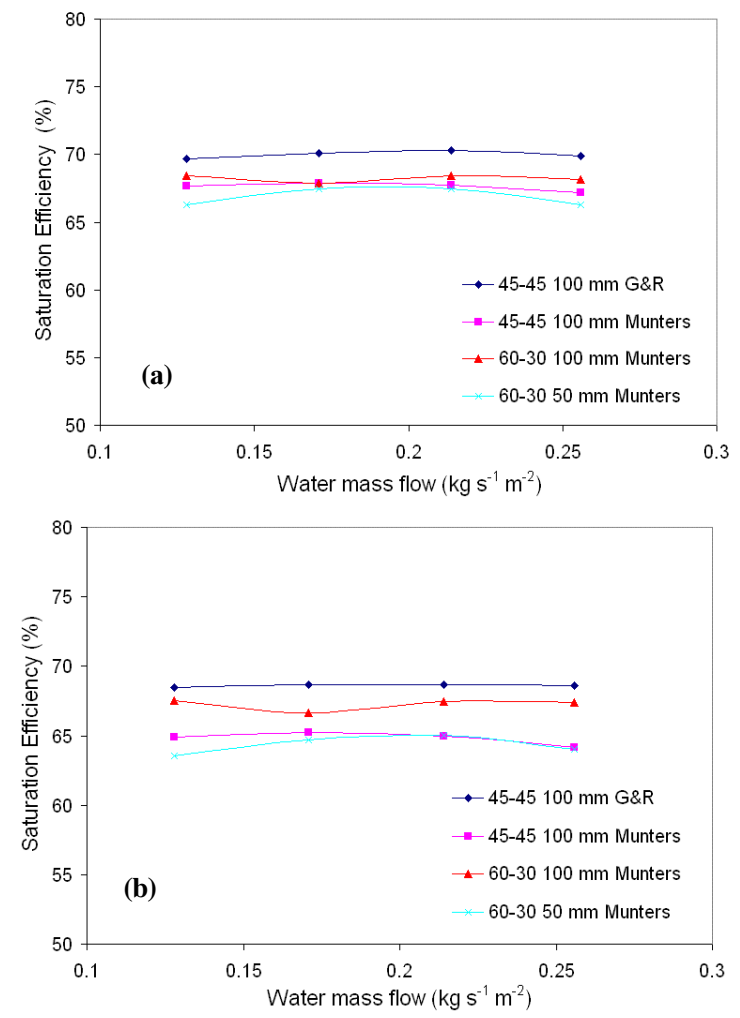

Figure 10. Effect of water flow on the air saturation efficiency for the four cellulose pads tested for air speeds through the pads of (a) $1 \mathrm{~m} \mathrm{~s}^{-1}$, and (b) $1.5 \mathrm{~m} \mathrm{~s}^{-1}$. 


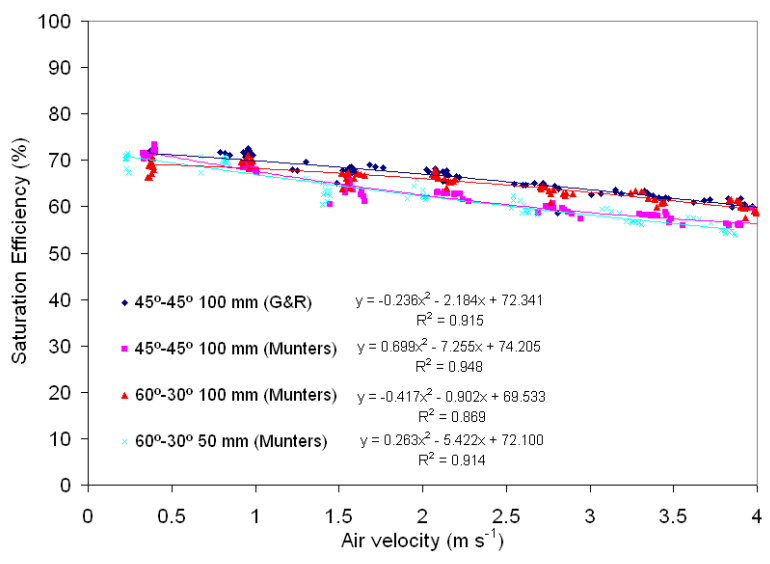

Figure 11. Effect of air speed through the pad on air saturation efficiency in the four cellulose pads for all the water flow rates applied.

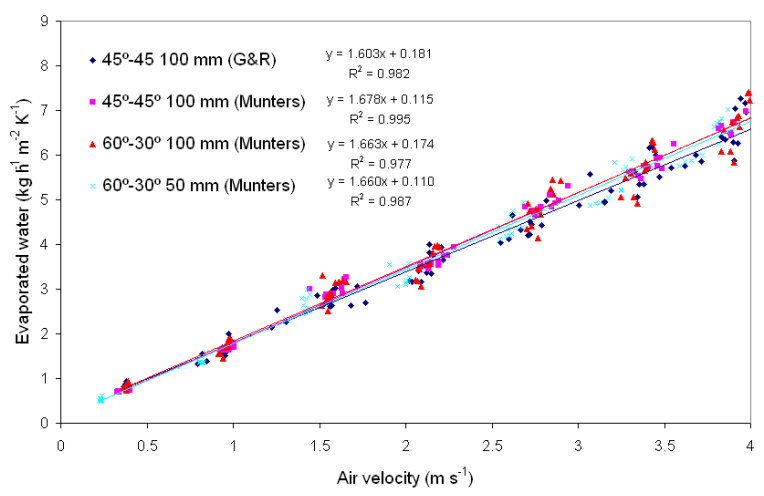

Figure 12. Effect of air speed through the pad on the amount of water evaporated ( $\mathrm{kg} \mathrm{h}^{-1} \mathrm{~K}^{-1}$ per $\mathrm{m}^{2}$ of pad area) for the four different pads at all water flow rates tested.

because it allows us to determine the right size for the pump and tank for water recirculation. The amount of water evaporated from the pad is related to the temperature and relative humidity of the outside air, to the air speed through the pad, and to the pad's structural characteristics (thickness, transfer surface, angle of incidence of the air, etc.).

Figure 12 shows the amount of evaporated water for the four types of pads studied at different air speeds and water flows, expressed in $\mathrm{kg}$ of water evaporated per hour per degree $\mathrm{K}$ of temperature reduction (eq. 19). At an air velocity of $1 \mathrm{~m} \mathrm{~s}^{-1}$, the amount of evaporated water is similar for all four cellulose pads: approximately $1.8 \mathrm{~kg} \mathrm{~h}^{-1} \mathrm{~K}^{-1}$ per square meter of pad area. However, as air speed increases, the amount of water evaporated also increases considerably, and small differences were observed among the four types of pads (fig. 12).

\section{Conclusion}

The methodology and the equipment developed for the tests of evaporative pads were proven suitable, versatile, and easy to handle.

We have obtained useful correlations that generalize the operation of commercial types of evaporative cellulose pads of differing geometrical characteristics (thickness, porosity, angles of incidence to the passage of air) and the flows through them of both air and water. The results obtained show that increasing the flow of water increases the pressure drop. However, the largest impacts are due to changes in air flow, since water flow has a relatively limited impact on the operation of the pads.

Moreover, when more water is applied than is evaporated, the heat and mass transfer coefficients, air saturation efficiency, and water consumption of the pads are influenced only by the air flow. Increasing the amount of water applied to the pads beyond the maximum evaporation rate has no beneficial effects.

We recommend a range of air speeds through the $100 \mathrm{~mm}$ pad of 1 to $1.5 \mathrm{~m} \mathrm{~s}^{-1}$, which is very similar to the ANSI/ ASABE recommendation of $1.27 \mathrm{~m} \mathrm{~s}^{-1}$ for $100 \mathrm{~mm}$ cellulose pads (ANSI/ASABE Standards, 2008). This range could be reduced by $25 \%$ for the $50 \mathrm{~mm}$ pads. We recommend installing ventilation fans that can be regulated to modify the air flow according to the requirements for renewal of air inside the greenhouse. To this end, variable-speed fans can be used, with the added advantage of considerable energy saving.

The amount of water evaporated by the pads increases when the temperature difference between the air entering and exiting the pad is greater $\left(T_{1}-T_{2}\right)$. This, in turn, depends on the climatic conditions of the outside air $\left(T_{1}\right.$ and $\left.T_{w b}\right)$ and the saturation efficiency of the pad $(\eta)$. The greater the air speed through the pad $(v)$ and the greater the exposed pad surface $\left(A_{f}\right)$, the greater the amount of water evaporated.

Over the range of air speeds between 1 and $1.5 \mathrm{~m} \mathrm{~s}^{-1}$, the pressure drop produced by the pads was between 3.9 and 11.25 Pa, depending on the type of pad and the water flow applied. On the other hand, the saturation efficiency varied between $64 \%$ and $70 \%$, and the amount of evaporated water ranged between 1.8 and $2.62 \mathrm{~kg} \mathrm{~h}^{-1} \mathrm{~K}^{-1}$ per square meter of pad area.

\section{ACKNOWLEDGEMENTS}

The authors wish to express their gratitude to the Spanish Ministerio de Educación y Ciencia for partially financing the present work by means of the research grants AGL200609068/AGR and BIA2006-12323.

\section{REFERENCES}

Al-Helal, I. M. 2007. Effects of ventilation rate on the environment of a fan-pad evaporatively cooled, shaded greenhouse in extreme arid climates. Applied Eng. in Agric. 23(2): 221-230.

Al-Sulaiman, F. 2002. Evaluation of the performance of local fibers in evaporative cooling. Energy Conv. Mgmt. 43(16): 2267-2273.

ANSI/ASABE Standards. 2008. EP406.4: Heating, ventilating and cooling greenhouses. St. Joseph, Mich.: ASABE.

Arbel, A., M. Barak, and A. Shklyar. 2003. Combination of forced ventilation and fogging greenhouses. Biosyst. Eng. 84(1): 45-55.

ASABE Standards. 2008. EP566.1: Guidelines for selection of energy-efficient agricultural ventilation fans. St. Joseph, Mich.: ASABE.

ASHRAE. 2005. ASHRAE Handbook of Fundamentals. Atlanta, Ga.: ASHRAE.

Beshkani, A., and R. Hosseini. 2006. Numerical modeling of rigid media evaporative cooler. Applied Therm. Eng. 26(5-6): 636643.

Dagtekin, M., C. Karaca, and Y. Yildiz. 2009. Performance characteristics of a pad evaporative cooling system in a broiler house in a Mediterranean climate. Biosyst. Eng. 103(1): 100-104. 
Dowdy, J. A., and N. S. Karabash. 1987. Experimental determination of heat and mass transfer coefficients in rigid impregnated cellulose evaporative media. ASHRAE Trans. 93(2): 382-395.

Dowdy, J. A., R. L. Reid, and E. T. Handy. 1986. Experimental determination of heat and mass transfer coefficients in aspen pads. ASHRAE Trans. 92(2a): 60-70.

El-Dessouky, H., A. A. Al-Haddad, and F. I. Al-Juwayhel. 1996. Thermal and hydraulic performance of a modified two-stage evaporative cooler. Renew. Energy 7(2): 165-176.

Fang, F. M., J. C. Chen, and Y. T. Hong. 2001. Experimental and analytical evaluation of flow in a square-to-square wind tunnel contraction. J. Wind Eng. Ind. Aerodyn. 89(3-4): 247-262.

Gunhan, T., V. Demir, and A. K. Yagcioglu. 2007. Evaluation of the suitability of some local materials as cooling pads. Biosyst. Eng. 96(3): 369-377.

Haeussermann, A., E. Hartung, T. Jungbluth, E. Vranken, J. M. Aerts, and D. Berckmans. 2007. Cooling effects and evaporation characteristics of fogging systems in an experimental piggery. Biosyst. Eng. 97(3): 395-405.

Holman, J. P. 2001. Heat Transfer. Columbus, Ohio: McGraw-Hill.

Hu, S. S., and B. J. Huang. 2005. Study of a high-efficiency residential split water-cooled air conditioner. Applied Thermal Eng. 25(11-12): 1599-1613.

Incropera, F. P., and D. P. DeWitt. 1999. Fundamentos de Transferencia de Calor. 4th ed. Mexico: Prentice Hall.

Kittas, C., T. Bartzanas, and A. Jaffrin. 2001. Greenhouse evaporative cooling: Measurements and data analysis. Trans. ASAE 44(3): 683-689.

Kittas, C., T. Bartzanas, and A. Jaffrin. 2003. Temperature gradients in a partially shaded large greenhouse equipped with evaporative cooling pads. Biosyst. Eng. 85(1): 87-94.

Kittas, C., M. Karamanis, and N. Katsoulas. 2005. Air temperature regime in a forced ventilated greenhouse with rose crop. Energy Build. 37(8): 807-812.

Koca, R. W., W. C. Hughes, and L. L. Christianson. 1991. Evaporative cooling pads: Test, procedure, and evaluation. Applied Eng. in Agric. 7(4): 485-090.

Lertsatitthanakorn, C., S. Rerngwongwitaya, and S. Soponronnarit. 2006. Field experiments and economic evaluation of an evaporative cooling system in a silkworm rearing house. Biosyst. Eng. 93(2): 213-219.

Li, S., and D. H. Willits. 2008. Comparing low-pressure and high-pressure fogging systems in naturally ventilated greenhouses. Biosyst. Eng. 101(1): 69-77.

Liao, C. M., and K. H. Chiu. 2002. Wind tunnel modeling the system performance of alternative evaporative cooling pads in Taiwan region. Build. Environ. 37(2): 177-187.

Milosavljevic, N., and P. Heikkilä. 2001. A comprehensive approach to cooling tower design. Appl. Therm. Eng. 21(9): 899-915.

Molina, F. D., D. L. Valera, and A. J. Álvarez. 2004. Measurement and simulation of climate inside Almería-type greenhouses using computational fluid dynamics. Agric. For. Meteorol. 125(1-2): 33-51.

Molina, F. D., D. L. Valera, A. J. Álvarez, and A. Madueño. 2006. A wind tunnel study of airflow through horticultural crops: Determination of the drag coefficient. Biosyst. Eng. 93(4): 447-457.

Sabeh, N. C., G. A. Giacomelli, and C. Kubota. 2007. Water use by greenhouse evaporative cooling systems in a semi-arid climate. In Proc. 2007 ASABE Annual Meeting. St. Joseph, Mich.: ASABE.

Sethi, V. P., and S. K. Sharma. 2007a. Survey of cooling technologies for worldwide agricultural greenhouse applications. Solar Energy 81(12): 1447-1459.

Sethi, V. P., and S. K. Sharma. 2007b. Experimental and economic study of a greenhouse thermal control system using aquifer water. Energy Conv. Mgmt. 48(1): 306-319.
Valera, D. L., A. J. Álvarez, and F. D. Molina. 2006. Aerodynamic analysis of several insect-proof screens used in greenhouses. Spanish J. Agric. Res. 4(4): 273-279.

Valera, D. L., F. D. Molina, and A. J. Álvarez. 2008. Ahorro y eficiencia energética en invernaderos. Madrid, Spain: Ministerio de Industria, Turismo y Comercio.

Watt, J. R., and W. K. Brown. 1997. Evaporative Air Conditioning Handbook. 3rd ed., Lilburn, Ga.: Fairmont Press.

Willits, D. H. 2003. Cooling fan-ventilated greenhouses: A modelling study. Biosyst. Eng. 84(3): 315-329.

Zhukauskas, A. 1972. Heat transfer from tubes in cross flow. In Advances in Heat Transfer, 8: 93-160. New York, N.Y.: Academic Press.

\section{NomenClature}

$A=$ surface area per unit volume $\left(\mathrm{m}^{2} \mathrm{~m}^{-3}\right)$

$A_{f} \quad=$ face area of pad $\left(\mathrm{m}^{2}\right)$

$A_{s} \quad=$ surface area of pad media $\left(\mathrm{m}^{2}\right)$

$C_{p a} \quad=$ specific heat of dry air $\left(\mathrm{kJ} \mathrm{kg}^{-1} \mathrm{~K}^{-1}\right)$

$C_{w} \quad=$ pad water consumption $\left(\mathrm{kg} \mathrm{h}^{-1} \mathrm{~m}^{-2} \mathrm{~K}^{-1}\right)$

$D \quad=$ diffusion coefficient of water vapor into air $\left(\mathrm{m}^{2} \mathrm{~s}^{-1}\right)$

$h_{H} \quad=$ heat transfer coefficient $\left(\mathrm{W} \mathrm{m}^{-2} \mathrm{~K}^{-1}\right)$

$h_{M} \quad=$ mass transfer coefficient $\left(\mathrm{m} \mathrm{s}^{-1}\right)$

$h_{a 1}, h_{a 2}=$ inlet and outlet specific enthalpy of dry air, respectively $\left(\mathrm{kJ} \mathrm{kg}^{-1}\right)$

$h_{v 1}, h_{v 2}=$ inlet and outlet enthalpy of saturated water vapor, respectively $\left(\mathrm{kJ} \mathrm{kg}^{-1}\right)$

$h_{w b} \quad=$ enthalpy of saturated water vapor at thermodynamic wet-bulb temperature of the inlet air $\left(T_{w b}\right)\left(\mathrm{kJ} \mathrm{kg}^{-1}\right)$

$k=$ thermal conductivity of dry air $\left(\mathrm{W} \mathrm{m}^{-1} \mathrm{~K}^{-1}\right)$

$l=$ pad thickness $(\mathrm{m})$

le $\quad=$ characteristic length of pad $(\mathrm{m})$

Le $\quad=$ Lewis number (dimensionless)

$m_{a} \quad=$ air mass flow rate $\left(\mathrm{kg} \mathrm{h}^{-1}\right)$

$m_{e} \quad=$ water evaporation rate $\left(\mathrm{kg} \mathrm{h}^{-1}\right)$

$m_{v 1}, m_{v 2}=$ inlet and outlet water vapor flow rate, respectively $\left(\mathrm{kg} \mathrm{h}^{-1}\right)$

$\mathrm{Nu} \quad=$ Nusselt number (dimensionless)

$\mathrm{Pr} \quad=$ Prandtl number (dimensionless)

$q \quad=$ heat transfer $\operatorname{rate}(\mathrm{W})$

$Q_{a} \quad=$ volumetric air flow rate $\left(\mathrm{m}^{3} \mathrm{~h}^{-1}\right)$

$Q_{w} \quad=$ mass water flow rate $\left(\mathrm{m}^{3} \mathrm{~h}^{-1}\right)$

$\mathrm{Re} \quad=$ Reynolds number (dimensionless)

$\mathrm{R}^{2} \quad=$ coefficient of determination

Sc = Schmidt number (dimensionless)

Sh = Sherwood number (dimensionless)

$T_{1}, T_{2}=$ inlet and outlet dry-bulb temperature $(\mathrm{K})$

$T_{w b}=$ thermodynamic wet-bulb temperature of the inlet air

ud $=$ number of sheets

$v \quad=$ air velocity $\left(\mathrm{m} \mathrm{s}^{-1}\right)$

$V \quad=$ volume occupied by the evaporative pad media $\left(\mathrm{m}^{3}\right)$

$W_{1}, W_{2}=$ inlet and outlet humidity ratio, respectively $\left(\mathrm{kg}_{w} \mathrm{~kg}_{a}^{-1}\right)$

\section{GREEK LETTERS}

$\alpha=$ thermal diffusivity $\left(\mathrm{m}^{2} \mathrm{~s}^{-1}\right)$

$\Delta P=$ static pressure $\operatorname{drop}(\mathrm{Pa})$ 
$\Delta T_{l m}=\log$ mean temperature difference $(\mathrm{K})$

$\Delta \rho_{v} \quad=\log$ mean mass density difference $\left(\mathrm{kg} \mathrm{m}^{-3}\right)$

$\eta \quad=$ saturation efficiency $(\%)$

$v \quad=$ kinematic viscosity $\left(\mathrm{m}^{2} \mathrm{~s}^{-1}\right)$

$\rho_{a} \quad=$ mass density of air $\left(\mathrm{kg} \mathrm{m}^{-3}\right)$ $\rho_{v 1}, \rho_{v 2}=$ density of water vapor in the airstream before and alter the test section $\left(\mathrm{kg} \mathrm{m}^{-3}\right)$

$\rho_{w b} \quad=$ saturation density of water vapor at the wet bulb temperature $\left(\mathrm{kg} \mathrm{m}^{-3}\right)$ 